Two Poems by Wendell Berry

\title{
The Illumination of the Kentucky \\ Mountain Craftsman, Chester Cornett
}

\author{
Alone, he has come to the end \\ of the handing down of his art, \\ the time having little use \\ for such skill as his, his land \\ seeded with lies and scars. \\ So much has he suffered \\ in his flesh that the end of time, \\ the signs being fulfilled, \\ the unsealing of the seals, \\ seems only to be borne \\ as he has borne the rest. \\ On the mountain top, stunning \\ him like the glance of God, \\ the lightning struck him. Entering \\ at the big tendons of his wrists, \\ it has stayed in his body \\ so that the insects no longer \\ bite him, and in the night \\ he is not afraid any more.
}

\section{A Failure}

They are gone, the wild

lilies that stood here in the years past. For the loss of meeting them again, I am less. Will they return next year? Will I? I needed to find them here, unfailing, in balanced, tensed, mottled, airy, proud vibrance of ash. 